\title{
Towards better understanding of context-aware knowledge transformation
}

\author{
Mieczysław Owoc \\ Wroclaw University of Economics, \\ ul. Komandorska 118/120, \\ 53-345 Wroclaw, Poland \\ Email: mieczyslaw.owoc@ue.wroc.pl
}

\author{
Paweł Weichbroth \\ Gdańsk University of Technology, \\ ul. Narutowicza 11/12, \\ 80-233 Gdansk, Poland \\ Email: pawel.weichbroth@zie.pg.gda.pl
}

\author{
Karol Żuralski \\ WSB University of Gdansk, \\ ul. Aleja Grunwaldzka 238A, \\ 80-266 Gdańsk, Poland \\ Email:kzuralski@wsb.gda.pl
}

\begin{abstract}
Considering different aspects of knowledge functioning, context is poorly understood in spite of intuitively identifying this concept with environmental recognition. For dynamic knowledge, context especially seems to be an essential factor of change. Investigation on the impact of context on knowledge dynamics or more generally on the relationship between knowledge and its contextual interpretation is important in order to understand knowledge dynamics. The aim of this paper is to research and examine the nature of knowledge transformation (a specific sort of life-cycle), and to identify contextual factors affecting knowledge dynamics.
\end{abstract}

\section{INTRODUCTION}

$\mathrm{K}$ NOWLEDGE is valuable - something we all agree on, but this agreement abruptly ends when we attempt to answer the primary question "what is knowledge?". Indeed, in ancient times, philosophers like Plato and Aristotle formulated different theories of knowledge, yet still today there is no common agreement on the definition of knowledge, and even proudly announced proposals are far from rationale, providing poor semantic and biased forms. Nevertheless, this does not discourage live discussions on its nature among scholars and practitioners, the results of which begin from basic definitions and end with complex artificial intelligence $(\mathrm{AI})$ methods and techniques.

In the past few years, authors have been conducting research in the scope of AI, knowledge discovery from databases (KDD) and knowledge management (KM). One of the emerging issues identified, with far reaching consequences, is context, which, by grounding the meaning and understanding of knowledge, enables knowledge to be transformed in particular dimensions, i.e. space, time or situation.

We used content analysis to examine the existing literature in the framed domain and time extent from 2000 to 2016. Our search for the adequate literature embraced various bibliographic databases, e.g. the Association for Computing Machinery (ACM), the ISI Web of Knowledge, Scopus, and Springer Link. Furthermore, the empirical studies and technical reports were analyzed to gather evidence of existing context-aware applications and systems.

In this paper, our contribution includes the following findings. Firstly, there are particular contextual determinants that influence different entities and the process of knowledge transformation; the classification or grouping of determinants is a must in order to elaborate a valid method of knowledge development. Secondly, we observed that knowledge transformation is constructed on contextual de- terminants, where each is also classified to a particular type and evaluated to the extent of the awareness level of a particular organization.

The paper is organized as follows. In Section II, we provide two basic definitions. In the next Section, the nature of knowledge transformation is outlined. In Section IV, we introduce the idea of contextual factors. Finally, we provide a working example as an image of the discussed issue, with a conclusion in Section VI.

\section{BASIC DEFINITIONS}

\section{A. Knowledge}

In this elaboration, the term "knowledge" has a twofold definition, based on the broad types, implicit and explicit. The former is based on common sense, encompassing a variety of phenomena (e.g. the ability to walk or run), roughly what Polanyi referred to as "tacit knowledge", which cannot be captured in language as it is tied to the environment and set in culture and relationships [1]. The interpretation of such knowledge can be subjective [2] (when do you walk slow or fast?, and when do you start running?). On the contrary, the latter has a verbal or written form (e.g. procedure) and is relatively easy to communicate, codify, store and distribute; usually, explicit representation uses a predefined notation that enables gathered (generated) knowledge to be expressed consistently and completely [3] (e.g. in the form of the association rule: if a customer buys wheat bread then he/she also buys skimmed milk, with support 0,02 and confidence 0,85 ).

\section{B. Context}

Isaac Newton claims that space is distinct from body and that time passes constantly, with no regard to whether anything happens in the world. For this reason, absolute space and absolute time are basic properties of the universe, and are the preferred frame of reference - both are the essence of the context's substance. Some examples of space- and timeaware contextualization can be found in $[4,5,6]$.

To understand particular ambiguous terms, at a glance some authors simply provide synonyms for them. In this case, "context" is often referred to as environment [7], location [8], or situation [9]. To these three nouns, we can respectively pin the following questions: ${ }^{(1)}$ what resources are you surrounded by?, (2) where are you?, and ${ }^{(3)}$ who are you with, or what are you doing? However, the context can be known or unknown, 
and if necessary may be identified "manually" by exploiting the expert (or domain knowledge), or "automatically" by using particular types of attributes [10].

\section{The EsSEnce Of KNOWLedge TRAnsformation}

The Knowledge Grid $(\mathrm{KG})$ is a promising new frontier that can be seen as an interpretable resource of information structures treated as a state at a specific time and place [11]. In general, this means a static state or a series of states with operations changing this state, which expresses the dynamic aspect of knowledge functioning [12]. Therefore, any development of the knowledge structure is due to a transformation covering its content, form or structure globally, (especially including network resources), or locally (identified with "granules" of knowledge). Knowledge transformation (KT) can be identified by its changes through relevant operators [13]. In a broader sense, we can put forward the entire knowledge life-cycle (divided into specific phases), while in a narrower scope it can be reduced to specific operations resulting in the creation of a new generation of knowledge content, structure or form [14].

There are several different approaches to defining the knowledge life-cycle (KLC) $[15,16,17]$. We share the view, along with $[18,19,20]$, of the four-phase KLC, namely: (1) discovering $\rightarrow$ (2) processing $\rightarrow$ (3) sharing $\rightarrow$ and (4) reusing $\rightarrow(1)$; with the assumption that the output should present "new" (previously unknown, non-trivial) knowledge, further processed and refined, usually in a collaborative way [21], which means moving again towards the cycle [22].

It is generally accepted that the discovery process consists of a sequence of iterative steps of data processing (data cleansing and integration, selection and transformation), data mining, evaluation models and their presentation and visualization [23]. Naturally, to a certain extent, it also requires user interaction with adequate expertise and experience. Some researchers [24] are of the opinion that the stage of knowledge processing is the second KLC phase, where the first one is to store and the third is to transform. The authors stress that despite the definition of a linear relationship between the phases, in practice, it is not always possible to clearly indicate the end of one and the beginning of the next. Moreover, the situation is complicated by possible different states of advancement of knowledge processed by individuals, groups or the entire organization, that work together in one environment of the knowledge grid. This creates the necessary conditions for the two-way and multilateral exchange of knowledge between entities.

For any organization, the challenge is to acquire new knowledge [25] (e.g. to solve a problem, to know the specifications of the market or to forecast customer behavior), which can be "produced" by employees (sometimes experts), or discovered from data repositories. The next step in the process of knowledge discovery from databases is the integration of heterogeneous sources of knowledge and the reinstallation of their combined analysis, which ultimately aims at generating "new" resources. This stage requires a number of problems to be solved such as the partial formalization and standardization of knowledge, taking into account different levels of detail and the detection and elimination of anomalies.

As part of the knowledge discovery phase, the following operators can be performed: search, capture, generation and evaluation [26]. Examples of such operations refer to the preparation of a list of potential contractors of the project including ranking the involved enterprise. Naturally, specific knowledge evaluation criteria must be taken into account: about the performers, price parameters, timeliness of performance or quality of service [27].

The processing of knowledge in a more elementary approach applies to subsequent operations that in an important way may change its content, form and location [28]. Within this process, we can distinguish: storage, combination, separation and localization [29]. Considering the nature of the processing process through a network, each of these operations, representing various forms and possible levels of knowledge aggregation, refer to particular concepts, axioms, rules or methods [30]. They include assumptions concerning the criteria for the grouping of companies or the diversification of their characteristics according to their areas of activity. It is also possible to anticipate the need to involve companies essential in delivering services. Results can be in the form of knowledge conglomerates (knowledge of the companies cooperating). In each case, one can deal with the knowledge of the network, located in a variety of corporate portals [31].

Operations that constitute the sharing of knowledge are directly related to the participating entities and available resources, and consist of: selecting, locating, configuring and evaluating [32]. Each of these operations can be adapted via the knowledge network, addressed to specific demands of users e.g. to select specific companies, or the location of knowledge resources on the problem being solved, adequate to the task and evaluation of the generated knowledge.

The last of these life-cycle processes of knowledge re-use is a kind of a bridge between separate cycles. Its role is the consolidation, adjustment and localization of knowledge. This means, in practice, the improvement of existing and newly discovered resources in terms of their use in new conditions, taking into account aspects of localization.

An example of solutions meeting the requirements formulated in the knowledge life-cycle, and efficiently providing the relevant operations available through network architecture, is definitely the Knowledge Grid [33]. The model of KG architecture consists of three layers: the repository, services and applications [34]. The repository layer refers traditionally to the tasks associated with acquiring and storing knowledge. The second service layer allows the use of homogeneous and heterogeneous sources of information. Thus, it is comprised of scattered operations of the knowledge transformation. In the third layer application users can work actively with knowledge resources.

The added value of the use of such a system relates to accessing different knowledge resources i.e. know-what, 
TABle I. STRUCTURING THE CONTEXT - Dimensional ASPECT

\begin{tabular}{|l|l|}
\hline Dimension & \multicolumn{1}{|c|}{ Type of context } \\
\hline Internal & - Organizational infrastructure \\
& - Resource oriented \\
& - Customer oriented \\
\hline External & - Political and Social \\
& - Economic and Legal \\
& - Technological \\
& - Environmental \\
\hline \multicolumn{2}{|c}{ Source: [37] }
\end{tabular}

know-who, know-how and know-why, which are contextually-dependent [35]. Therefore, the transformation of the knowledge units or knowledge grids can be determined appropriately by the subject, object, method and motivation.

\section{CONTEXTUAl FACTORS For KNOWLEDGE DYNAMICS}

Before discussing the role of factors determining knowledge transformation, firstly we discuss the context role in this process. Generally speaking, a context is everything that forces the understanding and interpretation of a given concept [36]. The complexity of the context may be different, from a single concept to a complex description. In other words, any implicit or explicit information about the circumstance or situation which affects an entity [37].

Context awareness is sometimes very intuitive, coming from different environments where entities (people, organizations) can act. Especially when changes in an environment must be considered for actual or future variants of activities. In turn, contextual factors seem to be useful as representative of circumstances. More precisely: contextual factors (CF) can be defined as certain characteristics of circumstance or situation. This concept can be presented in a more detailed way. One interesting approach is proposed in [36], where the authors presented a structured framework of contextual factors, based on two dimensions and a context type, given in Table 1.

CF can be considered for a company by including particular acting entities. Similarly, we may formalize the influence of CF on effectiveness or performance by including relationships between entities and the like. No doubt contextual factors can be considered as more or less advanced structures.
To structure the context a framework needs to be prepared with well-recognized dimensions: internal and external.

The above-presented framework describes contextual factors in terms of potential perspectives sharing and using knowledge. For example, knowledge should be prepared to be useful for servicing different customers. Available knowledge should be useful for company activities in the event of changing economic parameters, or modified legal regulations. If any of the assumed contextual factors are modified, as a result, company knowledge must be transformed in order to be useful for new circumstances, such as organizational, economic or environmental.

Such flexibly prepared contextual factors must be coherent with a company's intellectual assets or even personal knowledge. The main quest is in which way contextual factors can influence, directly or indirectly, knowledge transformation. A good starting point is the analysis of tendencies - or better, determinants - on knowledge transformation.

\section{V.WORKING EXAMPLE}

The research was conducted on the problem of knowledge transformation taking place at the university. Following the earlier-presented dimensions of context and context types the influence of assumed context factors, the influence of the earlier-presented dimension of context is evaluated apart from the required level of awareness. The given examples reflect real cases from the academia sector. The influence on knowledge transformation as well as the required level of its awareness was expressed from low to high. The results are presented in Table 2.

Knowledge transformation typical for changes in organizational infrastructure refers to a redefinition of university hierarchy, in terms of tasks and dependencies among university units (impacts, progressive aspects, educational challenges and specialization requirements). More than that, agreements with staff members should be updated, and duties of particular divisions should be negotiated and accepted. In consequence, the influence of this factor on knowledge transformation is very high.

The impact of the second contextual determinant, defined at the medium level, is resource oriented. Knowledge about new resources should be delivered (and similarly, a bit changed); however, regulations about library resources usage are not essentially changed. The lowest level of influence of

TABLE II. OVERVIEW OF THE CONTEXTUAL FACTORS INFLUENCING KNOWLEDGE TRANSFORMATION

\begin{tabular}{|c|c|c|c|c|}
\hline $\begin{array}{c}\text { Context } \\
\text { dimension }\end{array}$ & Context type & Example of context & $\begin{array}{c}\text { Influence on knowledge } \\
\text { transformation }\end{array}$ & $\begin{array}{l}\text { Required level of } \\
\text { awareness }\end{array}$ \\
\hline Internal & $\begin{array}{l}\text { - } \begin{array}{c}\text { Organizational } \\
\text { infrastructure }\end{array} \\
\text { - }\end{array}$ & $\begin{array}{l}\text { - } \begin{array}{c}\text { Division in faculties and } \\
\text { departments }\end{array} \\
\text { - } \quad \text { New library built } \\
\text { - New specialization offered }\end{array}$ & $\begin{array}{l}\text { - } \text { High } \\
\text { - } \text { Medium } \\
\text { - } \text { High }\end{array}$ & $\begin{array}{l}\text { - } \text { High } \\
\text { - Medium } \\
\text { - High }\end{array}$ \\
\hline External & $\begin{array}{l}\text { - } \text { Political and social } \\
\text { - Economic and legal } \\
\text { - } \text { Technological } \\
\text { - } \\
\text { Environmental }\end{array}$ & $\begin{array}{l}\text { - University ranking } \\
\text { - Acquired new grants or funds } \\
\text { - Accreditation awarded } \\
\text { - New IT products implemented } \\
\text { - Attractive localization }\end{array}$ & $\begin{array}{l}\text { - } \text { Medium } \\
\text { - } \text { Medium } \\
\text { - High } \\
\text { - High } \\
\text { - } \text { Low }\end{array}$ & $\begin{array}{l}\text { - } \text { Low } \\
\text { - Low } \\
\text { - Medium } \\
\text { - High } \\
\text { - None }\end{array}$ \\
\hline
\end{tabular}


contextual determinants can be defined in the case of environmental aspects. An example of an attractive localization in fact does not change university knowledge. Thus, the influence on knowledge transformation was evaluated at the lowest level. The presented influence of contextual factors on knowledge transformation presented for the university can also be valid for companies from different sectors. Knowledge transformation operators should be addressed for particular objects, but the problem of presenting relationships between contextual factors and the knowledge management process seems to be determined by the application domain.

\section{CONCLUSIONS}

Contextual determinants are essential in knowledge transformation, and in particular:

- the transformation of knowledge, considered as several steps of activities, should be correlated with environmental components,

- there are contextual determinants that can influence different entities and processes (including knowledge transformation); some classification or grouping of the determinants is necessary in order to elaborate a successful method of knowledge development,

- tendencies in knowledge dynamics should be correlated with grouped contextual determinants. Synchronization should be kept between the discussed determinants and progress in knowledge transformation.

Future research will be devoted to the improvement of knowledge transformation operators and to the investigation of other relevant grouping methods of contextual factors.

\section{REFERENCES}

[1] M. Davies, Knowledge-Explicit, implicit and tacit: Philosophical as pects. International encyclopedia of the social \& behavioral sciences, 2015, pp. 74-90

[2] K. Marciniak, and M. Owoc, Knowledge Management in the Interactive Portal for Decision Makers on InKOM Example, International Science Index,9(1), 2015, pp. 705-712.

[3] M. Owoc, K. Hauke, and P. Weichbroth, Knowledge-Grid Modelling for Academic Purposes. IFIP International Workshop on Artificial Intelligence for Knowledge Management. Springer, 2015, pp. 1-14.

[4] N. K. Tran, A. Ceroni, N. Kanhabua, and C. Niederée, Time-travel Translator: Automatically Contextualizing News Articles. In Proceedings of the 24th International Conference on World Wide Web, ACM 2015 , pp. 247-250.

[5] A. Fuxman, et al., Contextual insights. Proceedings of the 23rd International Conference on WWW, ACM 2014, pp. 265-266.

[6] Z. Gantner, S. Rendle, and L. Schmidt-Thieme, Factorization models for context-/time-aware movie recommendations. Proceedings of the Workshop on Context-Aware Movie Recommendation, ACM 2010 pp. 14-19.

[7] Y. C. Hwang, R. D. Oh, and G. H. Ji, A Sensor Data Processing System for Mobile Application Based Wetland Environment Contextaware. In International Conference on Ubiquitous Computing and Multimedia Applications, Springer, 2011, pp. 245-254.

[8] J. Indulska, T. McFadden, M. Kind, and K. Henricksen, Scalable location management for context-aware systems. In IFIP International Conference on Distributed Applications and Interoperable Systems. Springer, 2003, pp. 224-235

[9] W. Qin, D. Zhang, Y. Shi, and K. Du, Combining user profiles and situation contexts for spontaneous service provision in smart assistive environments. Ubiquitous Intelligence and Computing, 2008, pp. 187-200.
[10] J. A. Jakubczyc, and M. L. Owoc, Contextual knowledge granularity. Proceedings of Informing Science \& IT Education Conference (InSITE), 2011, pp. 259-268.

[11] M. L. Owoc, Intelligent paradigm in grid computing. Knowledge Acquisition and Management. Research Papers No. 25, Publishing House of the Wroclaw University of Economics, 2008, pp. 113-121.

[12] H. Zhuge, Knowledge flow management for distributed team software development. Knowledge-Based Systems, 15(8), 2002, pp. 465-471.

[13] M. L. Owoc, and P. Weichbroth, Transformacje wiedzy sieciowej. Podstawy ontologiczne. (Knowledge Grid Transformation. Ontological Foundations). Knowledge in Enterprise Creativity. Czestochowa University of Technology, 2014, pp. 165-177.

[14] A. Bogner, and W. Menz, The theory-generating expert interview: epistemological interest, forms of knowledge, interaction. Interviewing experts, Palgrave Macmillan, 2009, pp. 43-80.

[15] J. M. Firestone, The New Knowledge Management: a paradigm and its problems. KT Web Connecting Knowledge Technology Communities, 2003, pp. 1-8.

[16] A. Lenci, The life cycle of knowledge. Ontology and the Lexicon. A Natural Language Processing Perspective. Cambridge University Press, Cambridge 2010, pp. 241-257.

[17] J. Birkinshaw, and T. Sheehan, Managing the knowledge life cycle. MIT Sloan management review, 44(1), 2002.

[18] P. Brezany, I. Janciak, A. Woehrer, and A.M. Tjoa, Gridminer: A framework for knowledge discovery on the grid-from a vision to design and implementation. Cracow Grid Workshop, 2004, pp.12-15.

[19] D. Stenholm, J. Landahl, and D. Bergsjö, D, Knowledge management life cycle: An individual's perspective. DS 77: Proceedings of the DESIGN 2014 13th International Design Conference, pp. 1905-1914.

[20] K. Möller, Lifecycle models of data-centric systems and domains: The abstract data lifecycle model. Sem. Web, 4(1), 2013, pp. 67-88.

[21] M. Zięba, E. Bolisani, M. Paiola, and E. Scarso, Searching for innovation knowledge: insight into KIBS companies. Knowledge Management Research \& Practice, 2017, pp. 1-12.

[22] J. Gołuchowski, Technologie informatyczne $w$ zarzadzaniu wiedza $w$ organizacji. Akademia Ekonomiczna w Katowicach, Katowice 2007.

[23] P. O. Prakash, and A. Jaya, Analyzing and predicting user behavior pattern from weblogs. International Journal of Applied Engineering Research, 11(9), 2016, pp. 6278-6283.

[24] P. R. Carlile, and E. S. Rebentisch, Into the black box: The knowledge transformation cycle. Management Science, 49 (9), 2003, pp. 1180-1195.

25] K. Leja, Wybrane aspekty zarzadzania wiedza w wyższej uczelni. [W:] Zarządzanie wiedzą. Wybrane problemy, WZiE PG, Gdańsk 2003, pp. 29-42.

[26] M. Alsqour, K. Matouk, and M. L Owoc, A survey of data warehouse architectures - Preliminary results. IEEE, 2012, pp. 1121-1126.

[27] J. Wielki, Modele wplywu przestrzeni elektronicznej na organizacje gospodarcze. Wydawnictwo UE we Wrocławiu, Wrocław 2012.

[28] M. Hernes, A. Chojnacka-Komorowska, and K. Matouk Przetwarzanie wiedzy nieustrukturalizowanej $w$ obszarze e-bankingu. Ekonomiczne Problemy Usług, Wydawnictwo Naukowe Uniwersytetu Szczecińskiego 122, 2016, pp. 247-258

[29] M. Nycz, and M. L. Owoc, Pozyskiwanie wiedzy i zarzadzanie wiedza. Wydawnictwo Uniwersytetu Ekonomicznego, Wrocław 2010.

[30] Y. Li, and Z. Lu, Ontology-based universal knowledge grid: Enabling knowledge discovery and integration on the grid. Services Computing, IEEE 2004, pp. 557-560.

[31] J. Fazlagić, M. Sikorski, and A. Sala, Portale intranetowe. Zarzadzanie wiedza, kapital intelektualny, korzyści dla pracowników $i$ dla organizacji. WZiE PG, Gdańsk 2014.

32] K. Hauke, M. L. Owoc, M. L., and M. Pondel, Building data mining models in the Oracle 9i environment. Proceedings of Informing Science and IT Education, 2009.

[33] M. Cannataro, D. Talia, and P. Trunfio, Knowledge grid: high performance knowledge discovery services on the grid. Grid Computing 2001, pp. 38-50.

[34] M. Cannataro, and D. Talia, Semantics and knowledge grids: building the next-generation grid. IEEE Intelligent Systems, 19(1), 2004, pp. 56-63.

[35] E. Brendel, Contextualism, relativism, and the semantics of knowledge ascriptions. Philos. Studies, 168(1), 2014, pp. 101-117.

[36] V. Akman, Rethinking context as a social construct. Journal of Pragmatics, vol. 32, 2000, pp. 743-759.

[37] D. Kronsbein, D. Meiser, and M. Leyer, Conceptualisation of Contextual Factors for Business Process Performance. Proceedings of the International MultiConference of Engineers and Computer Scientists, vol. 2, 2014. 